\title{
NIGERIAN ARCHITECTURAL CONSERVATION: A CASE FOR GRASS-ROOTS ENGAGEMENT FOR RENEWAL
}

\author{
C.O. OSASONA \\ Department of Architecture, Obafemi Awolowo University, Ile-Ife, Nigeria.
}

\begin{abstract}
The article explores various issues related to heritage architecture - particularly with respect to attitudes, resources for conservation, advantages, challenges and impact made to date - majorly in the context of the Nigerian nation state. It posits that though a wealth of outstanding buildings exists, a major factor limiting meaningful conservation appears to be indecision as to actual modus operandi, apart from financial and logistics constraints. Nigeria's British colonial experience is highlighted as a major source of non-traditional heritage architecture, giving rise to direct legacies of colonization, Brazilo-Portuguese-adapted architectural samples and the hybrid British-Sierra Leonean house type. These have impacted traditional building culture to create a virile vernacular. Specific examples of outstanding buildings (within a 60-km radius of Ile-Ife) are presented, highlighting their heritage qualities, in the light of the real threat of demolition. Analysis of samples is based on typical features; this provides a basis for identification of stylistic roots in the vernacular. The article concludes by suggesting the way forward as being one in which government still takes the lead, but massively mobilizes grassroots support for sustainability. With the large stock of heritage-grade residential buildings spread all over the country, renewal (for continued occupation and general utility) - rather than mere restoration for conservation - is clearly indicated.

Keywords: architectural conservation, British colonial architecture, grass-roots engagement for renewal, heritage architecture, Nigerian Brazilian architecture, Nigerian vernacular architecture, sustainable conservation.
\end{abstract}

\section{INTRODUCTION}

The term 'heritage architecture' commonly refers to buildings of a bygone era which are imbued with cultural significance; it usually follows that the related culture is desirous of preserving such buildings and puts structures in place to ensure this. Such 'cultural significance' invariably relates to the history or general identity of a people, serving to culturally locate them, by presenting their building practices, particularly in a historical context.

All over the world, different cultures have been able to identify such historic architectural icons and have succeeded in conserving them - to varying degrees of conformity with their original architectural identities. One common attribute of the apparent timelessness of these various structures is the concerted effort made to maintain them (implying heavy investments in time, money and personnel).

Relatively, in Africa (aside from the Egyptian pyramids), not too many heritage structures have gained international recognition; specifically, with respect to architecture, this is even more the case. Heritage sites, however, are to be found in various locations - albeit, with only 129 locations all over the continent being accorded UNESCO Heritage Site status (and most of them in North Africa). With respect to the continent's obnoxious Slave Trade history, heritage architecture (represented by forts and castles) is restricted to the Gulf of Guinea coast (particularly Ghana), while erstwhile colonial presence (translated into churches, mosques, mission houses, administrators' residences, trading posts, etc.) exists in every region of the continent. Where heritage architecture specifically relates to the pristine, traditional models, 
it is doubtful whether these are present in quantities substantial enough anywhere on the continent, to bear out a culture of conservation, with respect to them. Perhaps this is because most of such traditional forms of architecture, among many African cultures, are of materials and techniques incapable of sustaining a prolonged lifespan. Many cultures have resorted to confining such prototype indigenous built form to live museums - or, at worst, conventional museums of architecture.

Despite the advanced nature of architectural conservation in Europe, the United States and parts of Asia, it is not as well developed in Africa (as implied above). Most nations, African countries inclusive, have institutions responsible for (some level of) maintenance of cherished cultural monuments and artefacts; usually, this is in response to a consciousness to their tourism potentials. Nigeria, too, has structures in place, ostensibly catering to the preservation of its material culture, in order to promote the tourism industry. How effective these have been is part of what this article addresses.

\section{ARCHITECTURAL CONSERVATION IN NIGERIA}

Nigeria is a country of great diversity. From ethnicities to flora and fauna, the variety is wide. Corresponding to its cultural diversity, evidences of varied material culture abound. Similarly, a lot of differentiation can be found with respect to the indigenous architecture of the many ethnic groupings. From an earlier work [1], it has been established that the commonest building material is earth, traditionally used as either monolithic layers of cob, adobe (or terracotta) or wattle-and-daub construction. Similarly, roofs could be of earth (in the northern region, where shallow-domed roofs and vaults are frequently used because of relatively little rain); alternatively, they could be of plant fibres and leaves, over a framework of timber. Eaves were also pronounced to further promote sunshading and general protection of walls. Expectedly with indigenous architectural practices, terrain played a very important part in the built form evolved: in parts of the country with a pronounced rocky landscape, stone walling (covered with a conical thatch roof) provided the prevailing archetype. In the mid-Savanna sub-region, grass could be woven to produce matting for fence walling, as enclosure for buildings of more substantial material; similarly, dwelling units predicated on impermanent materials such as stalks of sorghum featured in parts of the Sahel Savanna. In swampy terrain, lightweight architecture based on the use of bamboo for walling and palm fronds for roof cladding was characteristic; such structures were propped up on stilts above the marshes. Till date - and despite Nigeria's general ability to hold its own with respect to international practices in architecture - such traditional structures account for more than $60 \%$ of the nation's vernacular builtscape.

\subsection{Attitudes to architectural conservation}

It is often opined that a right disposition to a challenge paves the way to ultimate victory. Conversely, nothing is as defeatist as negativity. Part of the success recorded by nations with a vibrant culture of heritage conservation stems from the general public understanding the value inherent in material culture. This has entailed decades of synergizing between concerned governments and people who treasured their cultural evolution enough to make an enduring statement about it. As such, it is doubtful if the pyramids are only important to Egypt because of the colossal annual financial returns to successive governments they generate; rather, they are culturally symbolic icons - relics the Egyptian masses daily identify with as defining their corporate existence, and about which the political fortunes of a sitting government could hang in the balance. 
The Nigerian context, sadly, leaves a lot to be desired. While apathy significantly describes the attitude of most Nigerians to material-heritage issues, successive governments share in the blame. To the public, 'culture' is only relevant when it does not socially situate one in an 'unprogressive' mode. For instance, despite the fact that, till date, many developed nations (e.g. the United Kingdom, France and the United States) still construct buildings of earth bricks, the upwardly mobile Nigerian considers it socially stigmatizing to do so now; the average Nigerian only has recourse to it if unavoidably constrained by cost. Stemming from this misconception, even inheritances of buildings constructed of earth (though fired and plastered over and despite outstanding typological or craftsmanship significance) are generally trivialized. This attitude is largely responsible for the rampant neglect of much of the nation's heritage architecture.

Despite the above, a small number of private concerns and families consider their heritage property worthy of restoration and general preservation. For instance, some heritage buildings on a map produced by LEGACY (an environmental-interest, not-for-profit concern in Nigeria), unlisted but under private patronage, are in commendable condition; these include Christ Church Cathedral, Holy Cross Cathedral and the Lumpkin House. The first two buildings belong to wealthy Christian missions; for the latter, LEGACY championed comprehensive restoration, eventually sponsored by Leventis Foundation. Thus, private institutions seem to be making more impact in respect of architectural conservation in Nigeria, than government. Though this is also true of nations like the United Kingdom, Italy and the United States, the scenarios are quite different: there, architectural conservation is virtually a national culture; individuals and corporate organizations view it almost as their community responsibility to invest in it, and invariably only assist the government (already with the political will but expectedly limited financial resources) to carry out this assignment. Conversely, in Nigeria, architectural conservation is far from being a national priority; as such, the economic advantages have not been thoroughly researched - implying there is no incentive for the private investor to act upon and no example to affect the individual's sensitivity and general disposition to such matters [1].

\subsubsection{The roles played by government and other institutions}

Government's lack of a significant conservation culture has become entrenched, despite policies, institutions and other administrative structures, ostensibly put in place. The major government agency responsible for heritage conservation in Nigeria today is the National Commission for Museums and Monuments (NCMM), established in 1990 by the federal government. At the level of states, the NCMM is assisted by museums and other cultural agencies. Its scope of duties covers overseeing the activities of 48 such museums (while gaining from their outpost dispositions). Despite the NCMM having been established relatively recently, Nigeria had not been without conservation activity predating its inception; the creation of the NCMM was actually an amalgamation of two former government agencies: the Antiquities Commission and the Federal Department of Antiquities. As far back as 1948, there was a national museum already established in Jos; correspondingly, the Ile-Ife museum was already fully functional by 1954 .

Currently, Nigeria does not have much of a heritage-architecture conservation culture; this is not for want of worthy material. Every geopolitical zone has its own pool of deserving buildings, either on the basis of age, historical associations or distinctive craftsmanship general parameters for adjudging a building worthy of conservation. LEGACY conducted a national survey of historical sites in 1999. Again, this project was sponsored by the Leventis Foundation (Nig.) Ltd. The NCMM assisted the project by supplying much-needed 
information. Further assisted by the Nigerian Conservation Foundation (NCF), LEGACY produced the first comprehensive map to be published in the country, showing the locations of Nigeria's heritage sites and how to get to them. Overall, the map shows the location of 48 national museums, 15 national parks and 129 historical sites. However, of the 129 historical sites shown, just 47 are actual buildings, while only 27 of these are listed by the NCMM [2] Fig. 5 shows the headquarters building of LEGACY.

\subsubsection{Challenges}

The challenges to a thriving architectural conservation culture in Nigeria are multifaceted; specifically, they range from economic, through appropriate personnel, to social issues. Nigeria, still a developing nation, arguably has greater challenges than 'refurbishing antiquated buildings' (as some would term 'heritage-architecture conservation'). Financial resources the governments are able to coax from the economy are ploughed into the greater social priorities of providing the teeming masses with such things as (appropriate and liveable) housing, potable water, universal education and basic healthcare delivery.

The issue of skilled personnel to implement architectural conservation and restoration is also pertinent. Globally, this is a specialized discipline. Currently in Nigeria, where there are any experts at all, they are few and far between. Professor John Godwin, who coordinated the restoration activities on the Lumpkin House, Lagos, worked with a team of artisans in the building trade, in conjunction with a few general construction professionals and enthusiastic LEGACY members; also, in his restoration efforts on the 'Ilojo Bar' (the 1880 ca. family house of Victor Olaiya, a famous Nigerian musician), he was assisted by a similar motley crew. John Godwin is an architect - not a conservation specialist; as such, all he could bring to the work was his over sixty years' working experience. See Figs 1-4.

Another major challenge heritage-architecture conservation faces in Nigeria presently is the social milieu in which the work is to be carried out. The average Nigerian would much

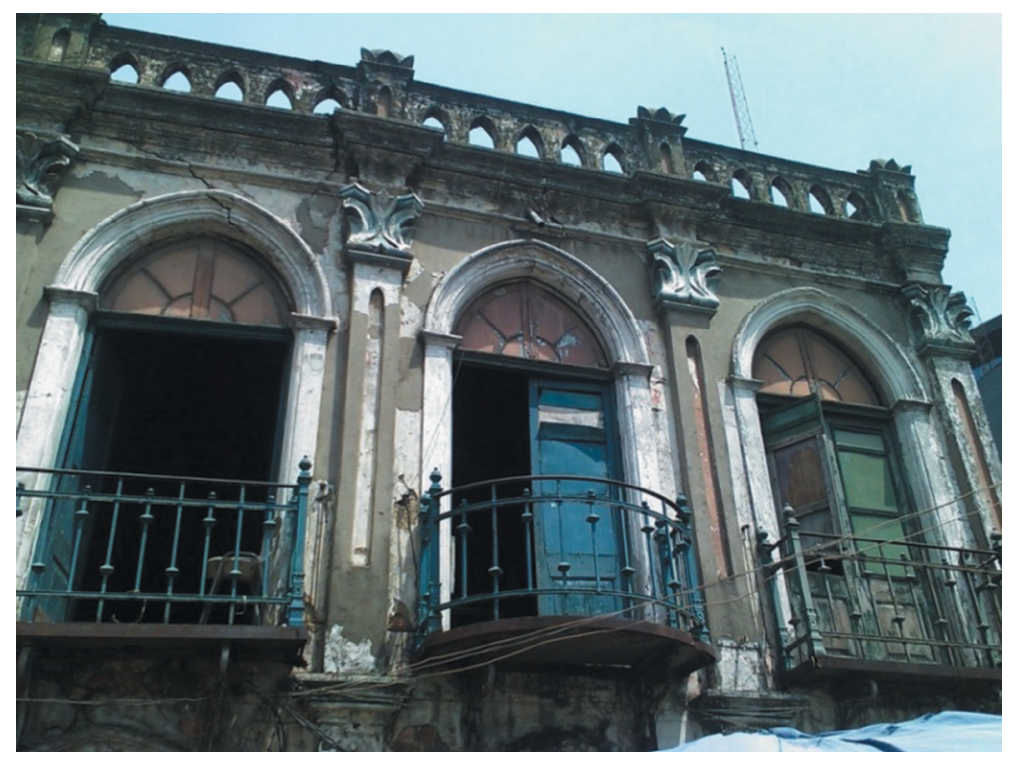

Figure 1: Ilojo Bar, Tinubu Square, Lagos. Before the restoration work in 2012 (D. Ale, 2012). 


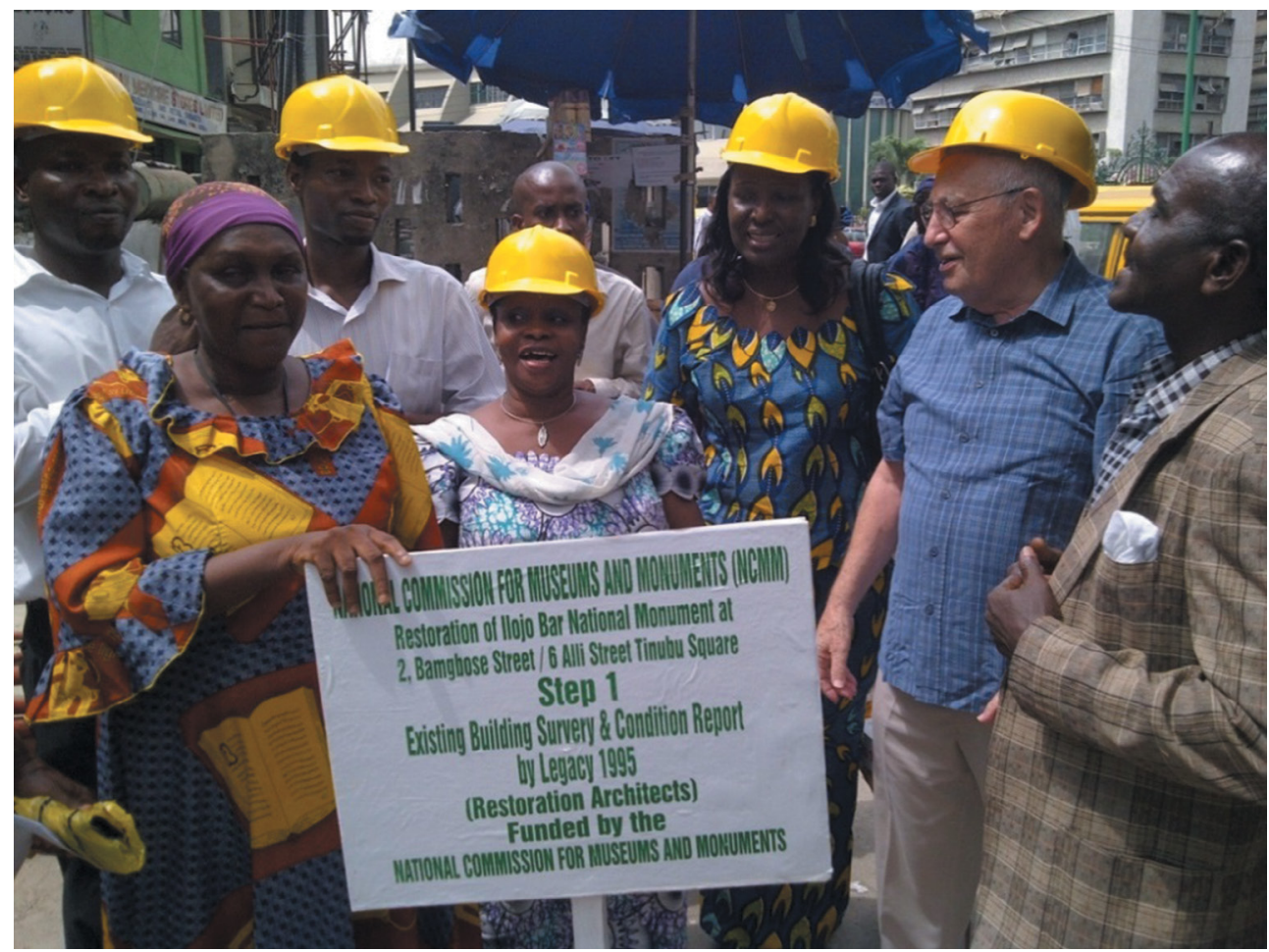

Figure 2: John Godwin (second right) with his 'motley crew', at the Ilojo Bar site (D. Ale, 2012).
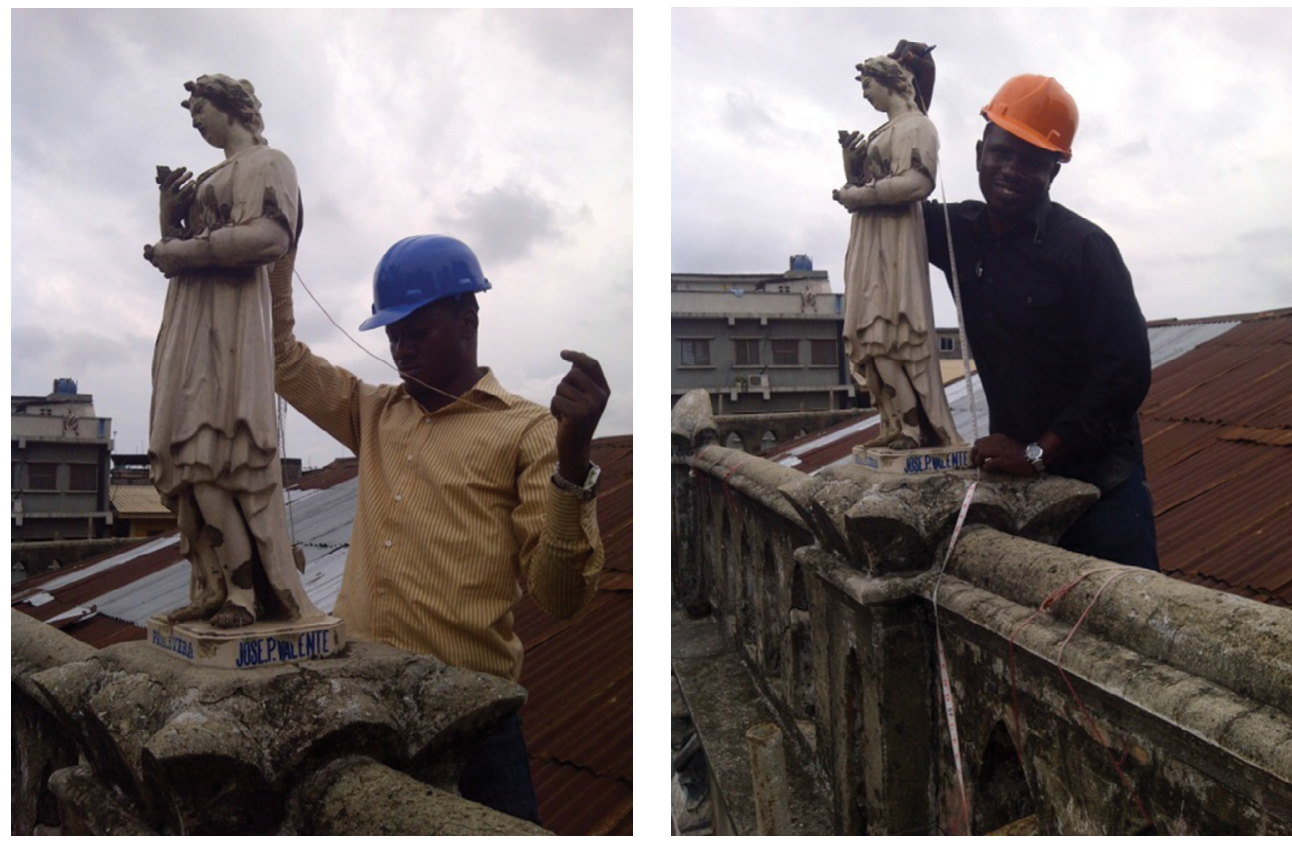

Figures 3 and 4: Line plumbing and measurement to replace a statue at the Ilojo Bar (D. Ale, 2012). 
rather confine such buildings to the past (and occasional memories) than have it clutter the modern landscape - not to talk of being saddled with the responsibility for its upkeep, even if only in part. Many reasons are responsible for this. The first is the unfortunate general mindset that such buildings symbolize underdevelopment and/or an unsavoury past. The second is the more complex issue of those who now own such buildings (by inheritance) generally not being actually on ground to oversee their welfare; some have taken up permanent residence in major cities of the nation, while others are in the diaspora - both categories ostensibly in search of greener pastures [1]. The third major reason for the entrenched social disenchantment with this category of property is the real financial challenge of even routine maintenance to the owner-occupiers, their relatives or tenants. Descendants of the original owner-occupiers of such buildings who have migrated to more urbanized parts of the same town (or outside, outright) busy themselves with keeping up with the lifestyle of their social environment - resulting in not having 'loose' money to plough into maintaining derelict property somewhere else.

\section{ILE-IFE AND ENVIRONS: A HERITAGE-ARCHITECTURE RESOURCE}

The origins of the Ifes are lost in antiquity, and though controversy surrounds the founding of the town, Biobaku [3] ascribes it to probably between AD 600 and 900. Others dilate on various aspects of the evolution of the ancient city. For instance, Jeffrey [4] submits that, by the 11th century, it had become a flourishing civilization, while Willet (basing his endorsement on carbon dating) confirms that, between the 9th and 12th centuries, Ife was already 'a settlement of substantial size' [5]. There are two popular viewpoints about the origins of Ile-Ife: one school of thought believes there were other settlements in that locality, before the rise to prominence of Oduduwa, the legendary warrior, regarded as the founding father of the Yoruba race; the other, a creation myth, acknowledges Oduduwa as the progenitor of the human race, sent by his father Olodumare (the Creator God), to assist in infusing order into a nebulous earth [6,7]; Ile-Ife was where he started carrying out the mandate to establish settlements.

Socio-culturally, Ife has global recognition, based essentially, on two significant phenomena: the first, as already mentioned, is that it symbolizes the origins of what Yoruba ethnicity entails. Annually, traditional festivals (such as the olojo) draw thousands of devotees from all over the country, and as far afield as Brazil, Cuba and the United States - thus making the town a rallying point, in matters of traditional belief systems and mode of worship. The second stems from the fact that the town's superlative craftsmanship in producing naturalistic terracotta and bronze sculptures has succeeded in drawing global attention to the ancient city; this has, doubtless, increased the town's potential for ethnological studies of Yoruba culture and generally conferred greater socio-cultural value on it. On both platforms, Ile-Ife is thus able to draw substantial mileage for international tourism.

\subsection{The Nigerian architectural landscape in historical context}

Like most parts of Southern Nigeria, Ile-Ife bears the physical imprint of unmistakable British colonization. The colonial presence, with respect to the built environment, had two basic manifestations: the first, as British direct involvement with transforming the landscape, by imposing their own archetypes for residence, recreation, worship, education, health care delivery, production and administration, among others; the second, as products of other cultures whose presence within the Nigerian indigenous polity had been facilitated by them. In 
the second category were the emancipados, returnee slaves from Cuba and Bahia in Brazil (rechristened aguda, by the people of Lagos), as well as the Saro, erstwhile British slaves repatriated to Freetown, Sierra Leone, who were eventually relocated to Lagos.

\subsubsection{Peculiarities of British colonial architecture}

Prior to British administrative presence in the country, the traditional builtscape had essentially featured residential architecture, with limited examples of community buildings and ancillary structures like granaries. The colonialists introduced architectural pluralism: schools, hospitals, banks, churches, courthouses, prisons, offices, factories and warehouses, among others, were constructed in various parts of the country, transforming the environment along British planning, engineering and general design principles. The distinguishing characteristics of this brand of architecture included the use of steep, hipped roofs (with shingles or cup-tiles), timber-boarded construction (or columned and massive masonry structuring), deep (and extensive) verandas, hooded windows and, initially, the integration of fireplaces and chimneys. Headrooms were lofty, and commonly timber-profiled. Rainwater run-off from roofs was channelled through rhones (roof gutters) either to ground-level sewers or into underground tanks. Before the introduction of glazing, windows were either timber panel shutters or timber-slatted jalousies; later, fenestration (and portals) was complemented with fanlights. Much later still, this arrangement was replaced by the sash or multi-paned glass casement window [8].

\subsubsection{Characteristics of British colonially facilitated architecture}

The 'Aguda influence' is typified by buildings constructed by repatriates from Brazil, Cuba and other Latin American countries, who were settled by the British in various parts of West Africa. Their being referred to as aguda, by the local populace in Lagos, was because they were predominantly Catholic (the word being the Yoruba colloquial for it). They were mostly skilled craftsmen, specializing in the highly ornate Hispano-Portuguese architecture popularized by the Brazilian building culture. Fired bricks and cement mortar were the favoured materials, with characteristic ornamental stucco sculpting reminiscent of the Baroque. It was also generally multi-storey, with complex roofs featuring attics and the use of dormer windows. Other characteristic features include balconies and timber staircases with ornate newels and balustrades; decorative highlighting of quoins, plinths and columns; relief murals; detached conveniences, and the use of an exaggerated, centrally located, double-loaded corridor. Today, this double-loaded corridor is a vestigial feature in much of Nigeria's vernacular architecture.

The 'Saro influence' derives from Freetown, Sierra Leone, established by the British in 1807, as a settlement for former slaves from the United Kingdom. Their culture generally harked back to their long sojourn in Britain. The building culture they instituted featured timber-framed and -boarded houses, single- or two-storey, usually with an en-framing veranda. Carved fascia boards and timber fretwork at the eaves were characteristic [8]. After repatriation of those who were able to trace their roots to Nigeria, in Lagos they were colloquially called Saro (probably the corrupted form of 'Sierra Leone'). The Saro were shrewd businessmen. They popularized the two-storey, mixed-use archetype (later adopted and adapted by British merchants), constructed either in wood or fired brick. This building model supported their predisposition to combine 'living and selling'; the first floor was their living quarters, while the ground floor serviced warehousing and other business spatial requirements. As with the Aguda legacy (with respect to the articulation of space), this living-and-selling 


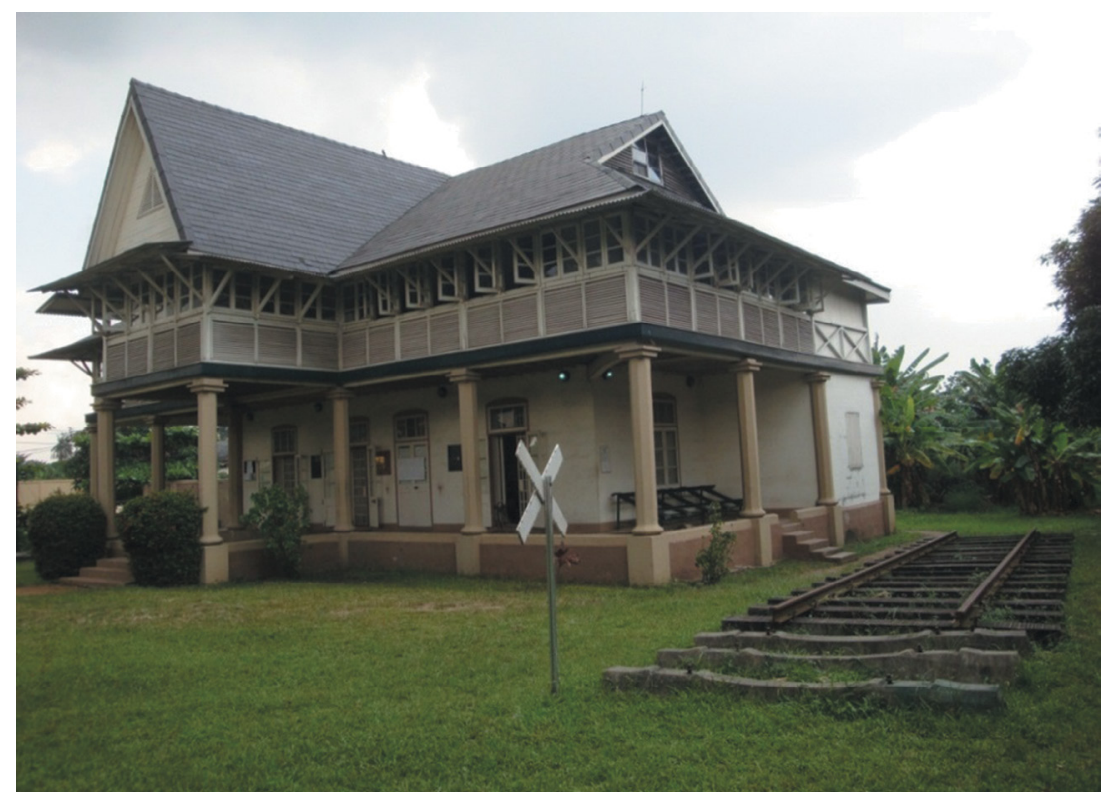

Figure 5: Jaekel House, Lagos. Typical colonial house, and formerly a Nigerian Railway Corporation headquarters. Now LEGACY headquarters (C. O. Osasona, 2012).

deployment in Saro architecture has become entrenched in Nigeria's vernacular-architecture practice (Figs 7 and 10).

\subsubsection{Ile-Ife's non-indigenous architectural heritage}

Ile-Ife and neighbouring towns have had colonial/colonially facilitated influence(s) on their built environment. Within Ife town (and a sixty $\mathrm{km}$ radius of its core) examples of both classes of influence abound. The most pronounced influence on vernacular architectural practices in the country is the Brazilian (or Afro-Brazilian, as the more immediate conditioning influence has come to be known). Justification for this assertion necessarily requires highlighting characteristic features which cumulatively have affected people's ultimate acceptance of the typology, conditioning them to appropriate it as the popular choice. For instance, the double-loaded-exaggerated-corridor morphology typifying this style lends itself extremely well to tenement, multi-family habitation. Also, from past researches conducted on architectural practices in the traditional African context, it has been established that ornamentation is not just integral, but transcends 'art for art's sake', being more a reflection of the total essence of intervening to define space for human appropriation $[9,10]$. Perhaps the preponderance of elemental ornamentation is part of the appeal of the Afro-Brazilian style to Nigerians.

Even though the Afro-Brazilian (or Aguda) style has been posited as being the more popular influence on Ile-Ife's (and Nigeria's) vernacular architectural practices, nevertheless, the Saro (or British) predisposition has also left significant imprints. Notable among these is the spontaneous integration of shops and other business spaces in typical residences - thus catering to a living-and-selling disposition (already highlighted as being justification for the Saro deployment of space in buildings). 


\section{ANALYSIS OF SAMPLES OF HERITAGE ARCHITECTURE}

The scope of the present work will not allow for a comprehensive cataloguing of all samples of heritage architecture, worthy of spotlighting, even within Ile-Ife's immediate environs. However, to give a general overview, analyses of three (3) specific samples in the AfroBrazilian style are presented here.

\subsection{Ile Adagbadanla, Ayeye, Ibadan}

Characteristically ornate, Ile Adagbadanla, 'the house of he who makes elaborate robes' (presumably for himself), displays the essentials of the Brazilian Style, a few generations on. However, in several ways, it is atypical, uniquely pre-empting much later models in layout. Situated in a densely populated part of Ibadan, relatively close to the city's traditional core, it was constructed in the early 1950 s.

In its floor plans, the building could pass for a semi-detached tenement complex, on two levels. However, rather than the two corridors being back to back, they are separated by another tunnel-like space, contrary to modern rationalization of land and financial resources, and Afro-Brazilian floor plans closer to widespread vernacular practices. The usefulness of this passage is doubtful, as it leads to a blank wall at one end, and is not naturally lit or ventilated; even on the first floor, its narrowness does not benefit from the light filtering through from the veranda. Generally, lighting in the building is very low, similar to the situation in the rooms of a typical traditional Yoruba impluvium-courtyard house.

Despite this negation of good design principles, Ile Adagbadanla presents a very interesting spatial layout: overall, there are 32 living spaces in the tenement complex. Though only four of them are designated 'parlour' (i.e. living room), the arrangement is flexible enough for a tenant to take two adjoining spaces, using one for living-room activities and the other as a bedroom. Circulation to these bedrooms is facilitated by corridors which end on blank walls in one of the wings of the building. Straight-flight wooden staircases provide vertical circulation, occupying half of the $3 \mathrm{~m}$-wide (10 ft) corridors; another (shorter run) wooden staircase connects the first floor with an extensive roof veranda. A bedroom is typically $3 \mathrm{~m}^{2}$ (the indigenous Yoruba ese bata mewa, i.e. ' 10 feet by 10 feet') (Figs 6 and 7).

\subsection{Hammed Raji House, Oke Ayepe, Osogbo}

Built in the mid-1950s (and located in Osogbo, the capital city of Osun State), this house typifies the status quo, with respect to chances of survival of 'old buildings' in an urban/ peri-urban context. Most of the tenants of the building have already moved out, as the house had been sold - the first step to eventual demolition, paving the way for the construction of a 'modern' house.

Typically, in its heyday, it had been the residence of the house owner and his family, on the first floor, with the ground floor rented out to multi-tenants. The spatial configuration seems to support the prevalent polygamous family set-up: presumably, the landlord maintained a 'room-and-parlour' unit for his personal use, while each of his two wives had a similar provision for herself and her children. However, on the ground floor, a room-and-parlour arrangement would serve a whole family, regardless of number of children; ingenuity in handling socio-spatial dynamics determined the effectiveness of changes in space use and attendant family convenience [11].

Hammed Raji House presents an interesting blend of typical and atypical features. Its extra-large corridor (with rooms displaced to both sides of it) is typical. However, in making 


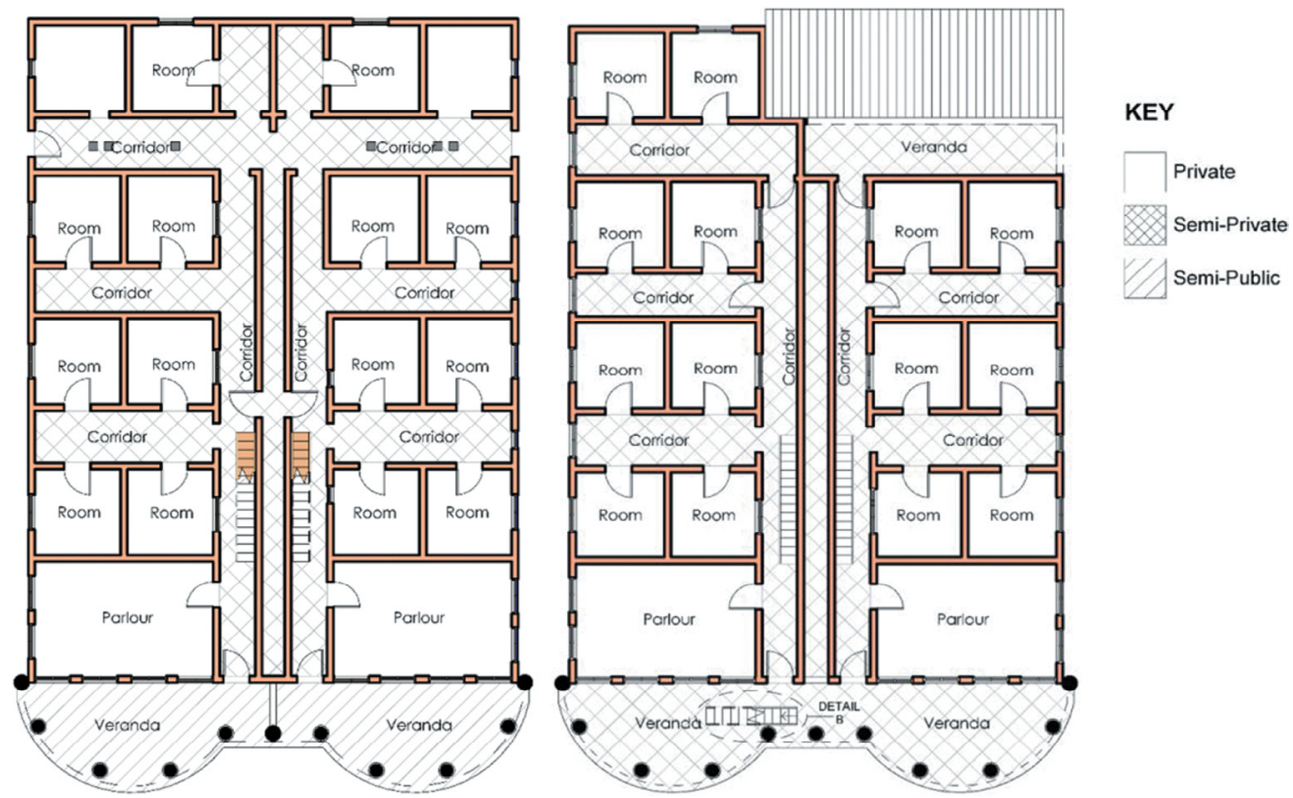

Figure 6: Ile Adagadanla. Ground and first-floor plans (D. O. Akinboboye, 2015).

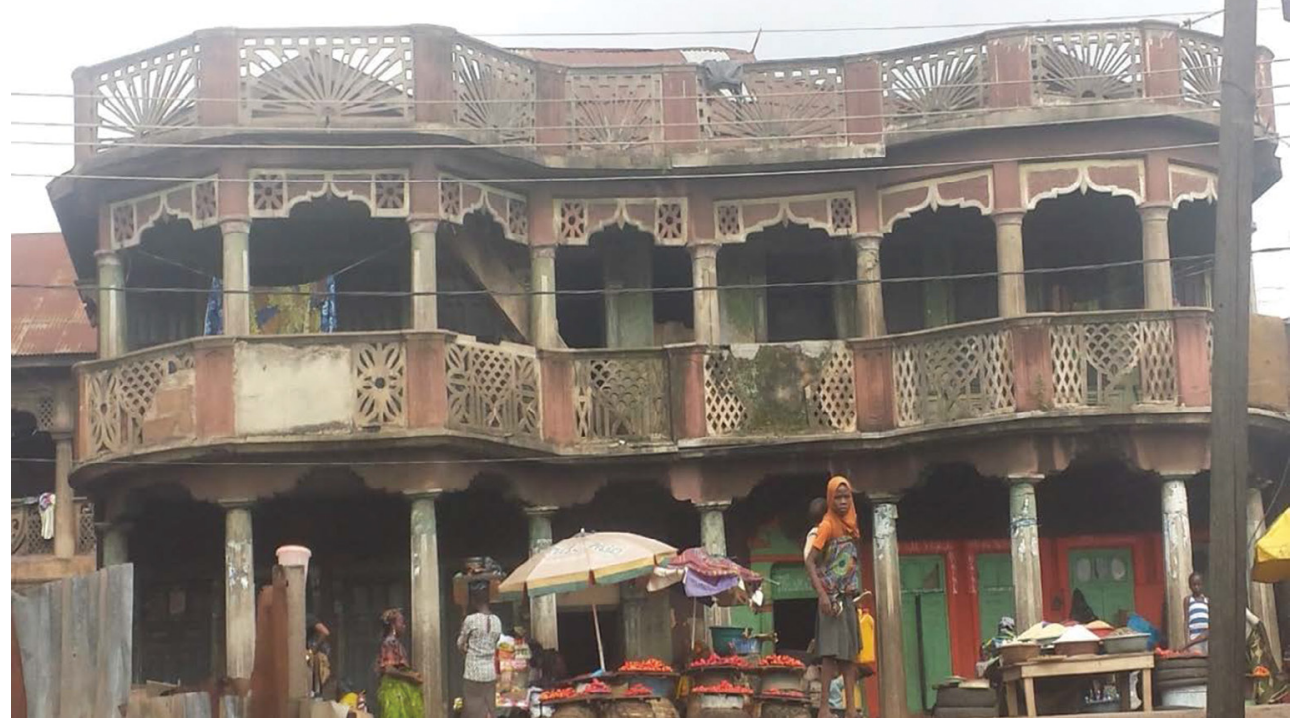

Figure 7: Ile Adagadanla, Ibadan. View from the street (D. O. Akinboboye, 2015).

the spaces in one-wing living rooms which lead into sleeping chambers (creating additional depth and a lopsided weighting) it loses characteristic symmetry. Also, contrary to the antecedent Brazilian Style, utilities are fully integrated, though confined to the rear. Again, bedroom spaces are not religiously square; rather, they are rectangular $(3 \times 3.6 \mathrm{~m})$. Some of the typical features include hooded windows, timber flooring and staircase, and elaborate 


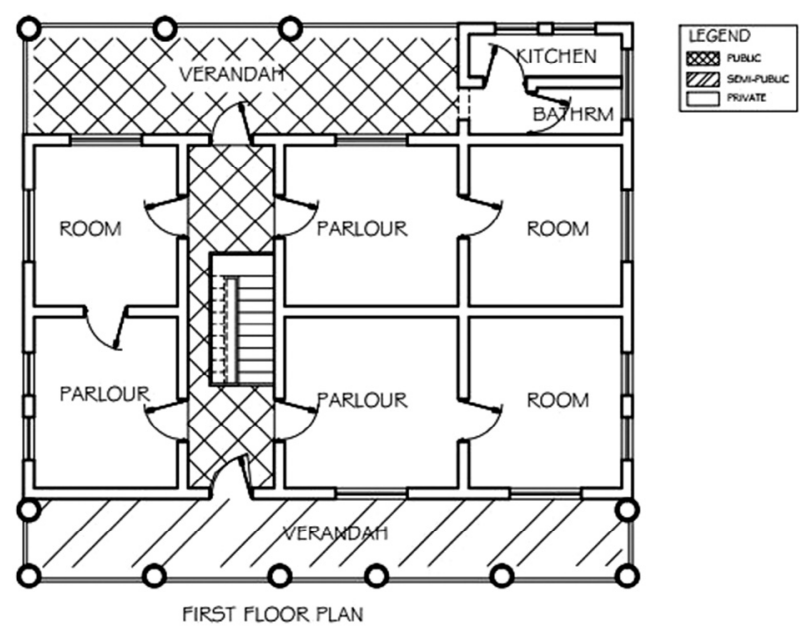

Figure 8: Hammed Raji House. Typical floor plan (O. O. Olaoye, 2015).

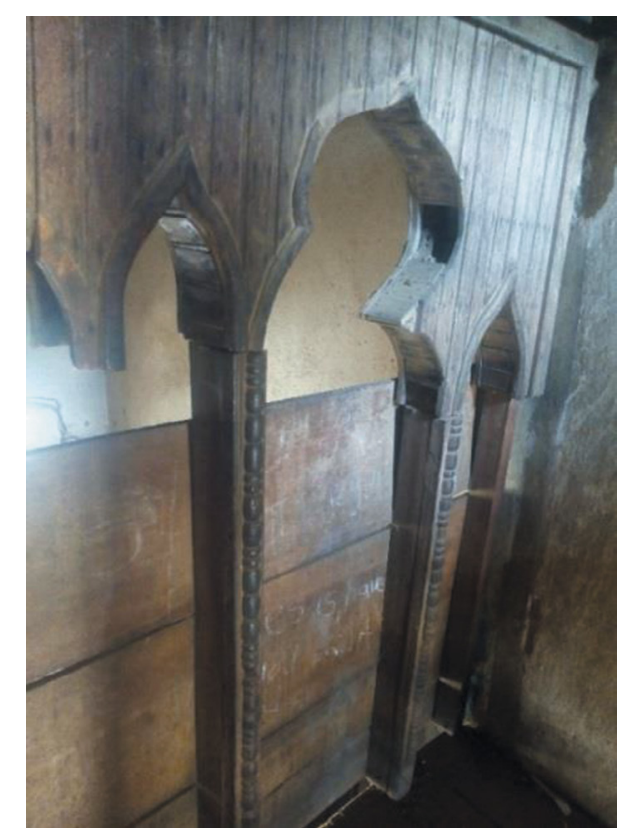

Figure 9: Timber arcade in stairwell (O. O. Olaoye, 2015).

concrete balustrading and stucco fretwork (Fig. 8). Figure 9 shows a unique and interesting feature: a carved timber arcade, separating the hinder regions of the stairwell from the foreground, on the ground floor; however, part of it has now been boarded up (Fig. 10).

\subsection{TIMI AKANJI HOUSE, OJA TIMI, EDE}

Located less than $30 \mathrm{~km}$ from Ile-Ife, the ancient town of Ede, like Osogbo, has excellent samples of the Afro-Brazilian. Timi is the title of the traditional ruler of the town, and though not the official residence of a reigning monarch, it was the private residence of Sanusi 


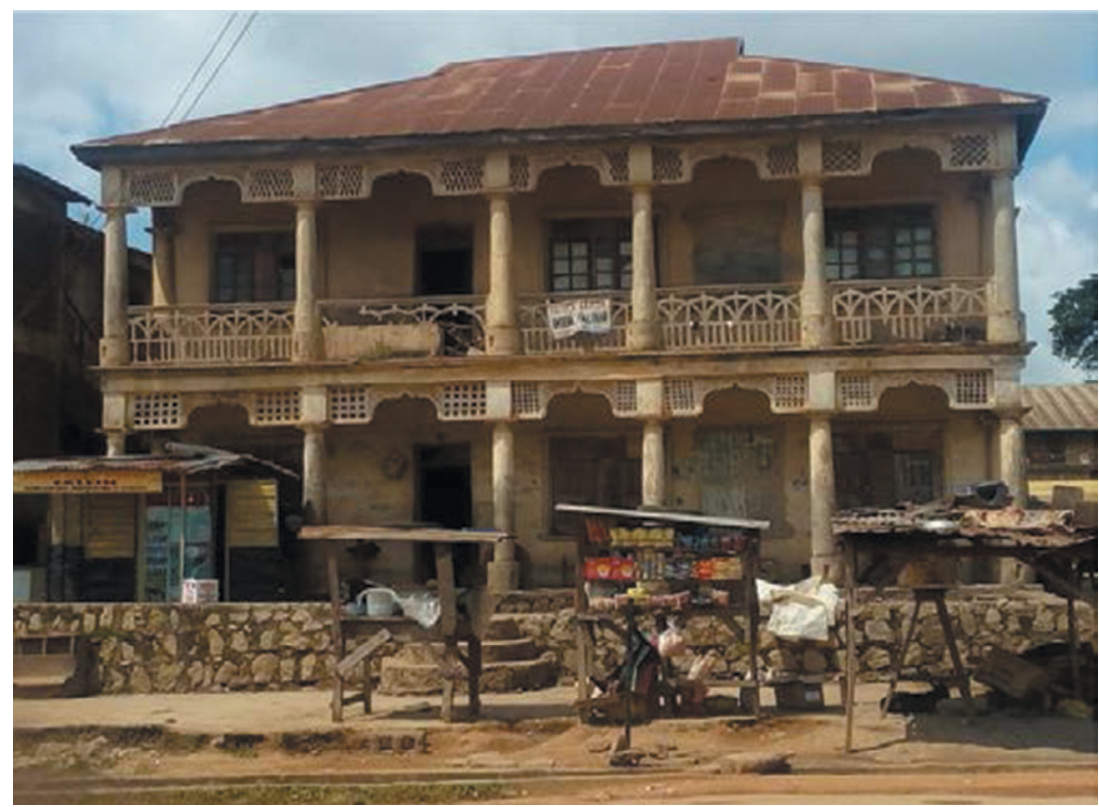

Figure 10: Hammed Raji House in Oke Ayepe area, Ososgbo (O. O. Olaoye, 2015).

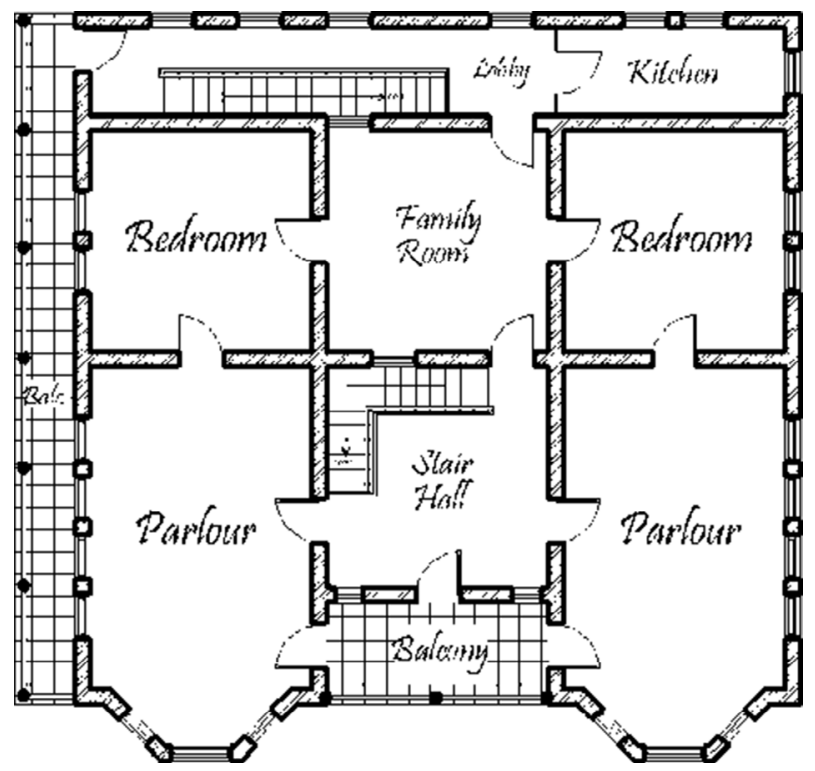

Figure 11: Akangbe House, Ede. First-floor plan (T. O. Ilyas, 2015).

Akangbe, the tenth ruler of Ede (1934-1945). Timi Agunyan-ma-se'su ('the king who produces pounded yam without recourse to yams'!), as he was fondly nicknamed, began construction of his personal residence in the late 1930s, very close to the official palace. On completion, it became the talk of the town, as it was the first of its kind in Ede. He housed some members of his extended family there, as well as occasional guests. 


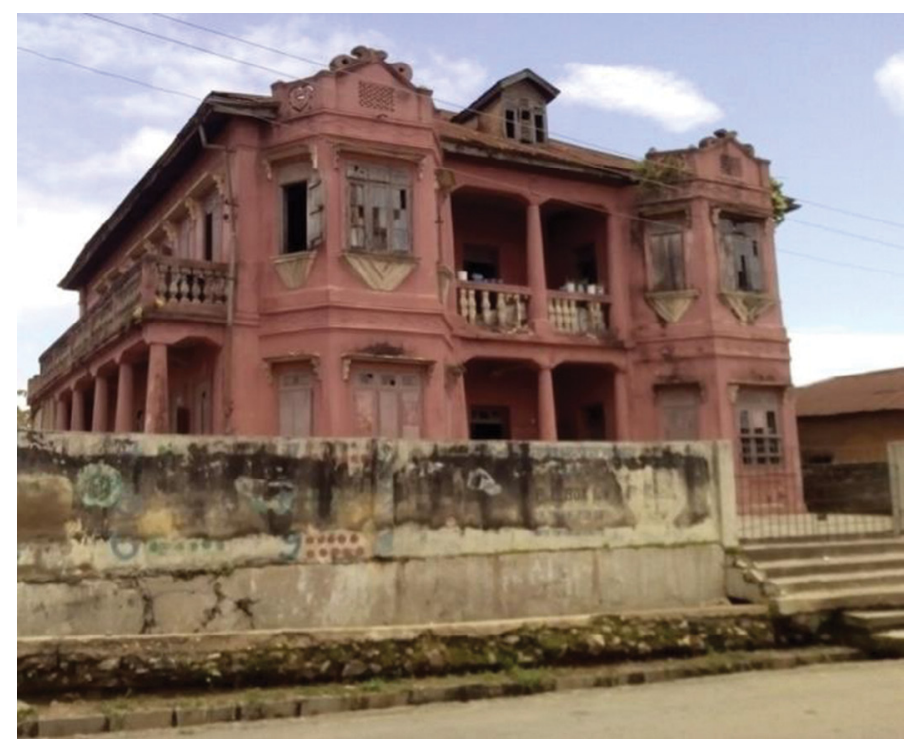

Figure 12: Akangbe House Street view.

In many respects, the Akangbe House (Fig. 11) is very typical: despite its two-storey configuration and general imposing masonry bulk, it comprises relatively few rooms and a very basic floor plan. Overall, there are only four living spaces per floor (with both floors identical in layout). The characteristic exaggerated double-loaded corridor here is, however, divided into two parts: the portion linking directly to the outside veranda is a stairwell, while the hinder part (though called a 'family room') is communal circulation space. Another point of departure is the integration of kitchens into the main house, though deployed to the rear (leaving only conveniences constituting the 'outhouse'); it is posited that this is an adaptation, over time, due to domestic exigencies. A straight-run staircase, attached to the back regions of the building, services the kitchens and provides an alternative means of vertical circulation (Fig. 12).

The Akangbe House is further distinguished by a flanking colonnade of bulky, square-base columns, supporting an extensive side sit-out. The overall composition is elevated (about 1.2 $\mathrm{m}$ ) above the street level, on a concrete podium, fenced, and is accessed by a flight of six steps. Literally capping the overall regal bearing of this building is a prominent attic, perched over the upper front veranda.

\section{THE CASE FOR CONSERVATION RESTORATION}

Apart from the issue of 'attitude' (discussed earlier), there are debates on the best approach to adopt - even where the attitude is supportive. It would 'solve everyone's problems' on the matter, if the government took on the responsibility, one hundred per cent. However, this has never been a favoured approach, as it is neither particularly progressive nor sustainable. Other issues are: should it merely be 'restoration-conservation' - or should it be a 'renewal' orientation? To further complicate issues, there is the germane dimension of many of these buildings being private property: to what extent should legitimate owners, on the one hand, be involved in financing the project and, on the other, have access to the restored building? These (and many more) considerations compound the phenomenon of heritage-architecture conservation. 
Restoration (for subsequent conservation) seeks to put a building back to its heyday glory. It studies its component materials and total formal characteristics and attempts to replace missing features. At the end of the exercise, a building should look as close to the original as possible. Revivalism, on the other hand, is more of an academic exercise, as it concerns itself with exactitude (of dimensions and overall formal composition) and general historical correctness. Documents of the original design of the building being intervened on are painstakingly studied, with a view to elucidating all pertinent information for an accurate restoration exercise. Slightly different from these two approaches is that of renewal. Here, the ultimate goal is to infuse an antique property with present-day functionality. Without tampering with its unique features (and 'heritage' integrity), modifications can be done to the building such that it will not just be a relic to be viewed, but actually be part of a locality's building stock in use.

The Venice Charter (1964), among other topical issues, outlined universally determined parameters for executing such interventions; these guidelines are variously referred to as 'articles'. The International Network for Traditional Building, Architecture and Urbanism (INTBAU), in 2006 and as a follow-up to the deliberations of the Venice Charter, organized a forum for revisiting the issues previously concluded by the Charter; this was informed by exigencies of the present dispensation (which the previous document could not have totally foreseen). The outcome of the 2006 deliberations was a revised 'charter' [12]. A summary of various submissions (particularly relating to restoration-conservation intervention) essentially portrays the concept of conservation/restoration as having significantly moved away from a slavish striving after authenticity, and treating architectural monuments as museum artefacts. The current perception favours informed and reinvigorating reuse (renewal) as the basis for conservation and restoration of old structures. They are authentic pieces of the contemporary, living urban (or rural) fabric - not just to be perceived of as artistic and historical (or other lyrical) symbols. Conclusively, to the extent to which the sixteen articles of the Venice Charter support a contextual, proactive and sustainable intervention, it would appear current discourses on conservation and restoration still support its provisions [13].

Even when the main issue of the approach to be adopted in extending the shelf life of a heritage building has been resolved, there is also the issue of the actual logistics of sustaining the tempo of the advantages inherent in doing so. Some of these advantages are examined below.

\subsection{Preservation of heritage architecture: Advantages}

Various authors have, over time, established the advantages inherent in conserving heritage architecture - among other issues. Harvey [14, p. 18], quoting Katherine Everett, posits that a building, as 'a work of art', constitutes the highest (i.e. greatest) expression of the human spirit (and, as such, every such structure is a great accomplishment) and adduces certain major advantages to architectural conservation, as listed below:

1. Such heritage structures exist as a historical continuum and provide psychological anchorage for a people, as (since they hark back to a time before they - and possibly generations before them - existed) they betoken permanence and stand as evidence of their evolution in material culture; essentially, such buildings contribute significantly in giving a people cultural identity;

2. Old buildings have real value - economic and social: being essentially over-structured, they are structurally safe, as well as acoustically, thermally and otherwise sound-implying that they can rationally be factored into the housing stock of a locality, thus ameliorating subsisting housing shortage; 
3. Where such buildings are historically (or typologically) significant - and of more than passable quality - their tourism potential can be fully tapped for optimum financial gains.

Additionally, within a contemporary setting (often featuring predictable and monotonous streetscapes), the presence of conserved old buildings provides visual relief - virtually tantamount to serendipity.

The financial returns from the tourism potential of heritage buildings is justification enough for investing in their conservation. However, the impracticability of conserving all heritage buildings is universally agreed. Thus, certain criteria have been identified for use in determining which buildings to conserve; these are historical significance, outstanding craftsmanship and typological significance. Similarly, Harvey [15] identifies three parameters for use in eliminating the temptation to engage in nostalgic conservation (i.e. conserving for 'old time's sake'). These are date, position and quality.

A building may be considered worthy of conservation, if it is associated with a significant incident in the history of a people, for example Elmina (St. George's) Castle, Ghana, built by the Portuguese in 1482, which was a fortress for holding slaves, for transportation to the Americas, during the Slave Trade. It has been preserved as both a national and global symbol, though commemorating an unfortunate chapter in human history. Outstanding craftsmanship displayed by an artefact, predisposes one to its conservation. 'Typological significance' posits that if a particular building marks the clearly recognizable beginning of an architectural style (or the equally unambiguous peak in its development), it deserves to be preserved for posterity. Harvey's 'date' yardstick argues that the oldest building should always be favoured, based on its rarity (by reason of age). He explains 'position' to mean that if a particular old building happens to be the only one in a given locality, it should not be demolished, but restored and subsequently maintained. 'Quality' relates to the universal appeal of excellent detailing [14, pp. 35-38].

\section{RENEWAL, THE WAY FORWARD FOR SUSTAINABLE CONSERVATION}

Architectural conservation, as a sustainable culture that holistically, adequately and appropriately caters for heritage buildings, needs grass-roots appeal and engagement. Whatever the subsisting governance, the people must be convinced of the value of the exercise, based on an understanding of the inherent value of such structures. Without this, even where the government has the logistical and financial capacities, the lack of support of the people will militate against its sustenance. Much may not be achievable where the people cherish their heritage structures, but the government is unable to support their interest in their conservation. However, this latter scenario is preferable, as overtures may be made to non-governmental concerns that have the financial wherewithal, for sponsorship.

Based on the extensive building stock that properly qualifies for restoration conservation (and the impracticability of government being solely responsible for the exercise and subsequent upkeep), the way forward appears to be an arrangement whereby owners of such heritage buildings are encouraged to keep them, and assisted in making them contemporarily serviceable. Much of the disenchantment with these buildings stems from their lack of modern amenities. Renewal of old homes will keep their quaint appeal, while infusing them with modern-day liveability and general contemporary relevance. In addition to a suggested initial financial assistance (which may be contractually agreed as a loan to be offset when such buildings again become liveable) professional architectural and engineering advice will be required to implement the necessary design changes and construction. 
A recent experience (vis-à-vis opting for renewal of a heritage building, rather than its mere restoration) sadly brings unresolved issues of the correct perception of the people into sharp focus. Ile Akogun, the official residence of Ile-Ife's equivalent of a Field Marshal, had been abandoned to dilapidation, for about ten years. Based on the incumbent title-holder having expressed a desire to occupy his official residence (if modern amenities could be integrated into it) a design proposal for its renewal was submitted in 2010 [13]. The proposal retained everything that was culturally symbolic and characteristically unique to the building, while fitting it with modern-day conveniences; additionally, more accommodation was provided. Sadly, based on 'social pressure', the Akogun's family was eventually persuaded to demolish the culturally iconic building, early in 2013 and, rather, opt for a brand new, 'totally modern' structure.

Though sustainable restoration-conservation of heritage architecture should not be totally government-driven, government has a major role to play. Among its key responsibilities in Nigeria, the government must first acknowledge the advantages inherent in heritagearchitecture conservation and develop the necessary political will to invest in it. Second, campaigns for appropriately sensitizing the masses (to offset the existing generally negative mindset) must be embarked upon; additionally, appropriate policies need to be crafted, featuring home-grown solutions. Some such innovations could be pseudo-listing of privately owned heritage-class structures and the setting up of a 'restoration fund'.

On its part, the community should muster the will to cooperate with the government; people should actively work (in the spirit of such reorientation programmes) for a change in their disposition towards heritage architecture. Thus, it will not be difficult for individuals and families who possess such buildings to key into whatever government structure for their rehabilitation has been put in place. The new commitment to a heritage-conservation culture will ultimately translate to a rise in the generally available housing stock, significantly featuring buildings that have become structurally enhanced, aesthetically improved, essentially still culturally determined and thus, overwhelmingly acceptable.

\section{CONCLUSION}

The multifaceted nature of heritage-architecture conservation has been discussed. In particular, the apparently contradictory positions traditionally held on the phenomenon have been set out. Heritage buildings in Nigeria deserve to be given an opportunity for their lives to be extended; the advantages inherent in this have been adequately discussed. Posterity also deserves to be given the opportunity to experience these structures, while they may be conserved by continuous maintenance. The capital-intensive nature of appropriate (and adequate) conservation-restoration works - coupled with the need for social integration indicates it should be a partnership between government, non-governmental concerns and the community at large. Though, expectedly, the government should take the lead in such interventions, the grass-roots support that this partnership implies will ensure sustainability of the practice. Given the grave negative consequences for cultural identity (and proper social orientation, in general) of doing otherwise, it is submitted that the clarion call sounded in the above discourse is long overdue.

\section{ACKNOWLEDGMENT}

The author hereby wishes to acknowledge the contributions of postgraduate students of the Department of Architecture, Obafemi Awolowo University (referenced as appropriate, above) whose submissions on the course Vernacular Architecture in Nigeria provided some of the illustrations used. 


\section{REFERENCES}

[1] Osasona, C.O., Heritage architecture as domestic space: A tale of three buildings in Ile-Ife, Nigeria. International Journal of Sustainable Development and Planning, 10(1), Wessex Institute of Technology, Southampton, pp. 42-65, 2015. DOI: 10.2495/ SDP-V10-N1-42-65

[2] LEGACY, Historical Sites of Nigeria, LEGACY: Lagos, 1999.

[3] Biobaku, S. Origins of the Yoruba, Federal Information Service: Lagos, p. 21, 1955.

[4] Jeffery, M.D., When was Ile-Ife founded? The Nigerian Field Society, 23(1), pp. 21-23, 1958.

[5] Willet, F., African Art: An Introduction, Thames and Hudson: London, p. 367, 1971.

[6] Johnson, S., The History of the Yorubas, CSS Limited: Lagos, p. 15, 1921, 2001.

[7] Obateru, O.I., The Yoruba City in History: 11th Century to the Present, Penthouse Publications: Ibadan, p. 110, 2003.

[8] Osasona, C.O. \& Hyland, A.D.C., Colonial Architecture in Ile-Ife, Nigeria, Ibadan: Bookbuilders, Editions Africa, 2006.

[9] Denyer, S., African Traditional Architecture, Heinemann: New York, 1978.

[10] Osasona, C.O., The social context of decoration in Nigerian vernacular architecture. Nigeria Magazine, Lagos, 57(1 \& 2), pp. 86-93, 1989.

[11] Osasona, C.O., From Traditional Residential Architecture to the Vernacular: The Nigerian Experience, available at http://www.mudonline.org/aat/2007_documents/ AAT_Osasona, 2007 (accessed 27 May 2008).

[12] Hardy, M., The Venice Charter Revisited: Modernism, Conservation and Tradition in the 21st Century, Cambridge Scholars Publishing: Newcastle-upon-Tyne, 2008.

[13] Osasona, C.O., Ogunfolakan, B.O. \& Ewemade, F.O., The renewal of Ile Akogun in Ile-Ife, Nigeria: A paradigm for the conservation of Yoruba iconic architecture. Africa Habitat Review, 4(4), The Journal of the School of the Built Environment, University of Nairobi, Kenya, pp. 225-238, 2011.

[14] Harvey, J., Conservation of Buildings, John Baker Ltd.: London, 1972. 